DE

M E D I C I N A

T R O P I C A L

$\mathrm{DE}$

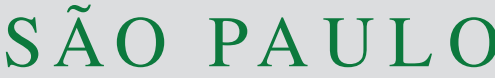

JOURNAL OF THE SÃO PAULO INSTITUTE OF TROPICAL MEDICINE

${ }^{1}$ Universidade Federal do Ceará, Faculdade de Medicina, Departamento de Medicina Clínica, Programa de Pós-Graduação em Ciências Médicas, Fortaleza, Ceará, Brazil

¿Universidade Federal do Ceará, Faculdade de Farmácia, Odontologia e Enfermagem, Laboratório de Nefrologia e Doenças Tropicais, Fortaleza, Ceará, Brazil

'Universidade de Fortaleza, Centro de Ciências da Saúde, Curso de Medicina, Programa de Pós-Graduação em Saúde Coletiva e Ciências Médicas, Fortaleza, Ceará, Brazil

${ }^{4}$ Universidade Federal do Ceará, Faculdade de Farmácia, Odontologia e Enfermagem, Programa de Pós-Graduação em Ciências Farmacêuticas, Fortaleza, Ceará, Brazil

Correspondence to: Geraldo Bezerra da Silva Junior

Universidade de Fortaleza, Centro de Ciências da Saúde, Curso de Medicina, Programa de Pós-Graduação em Saúde Coletiva e Ciências Médicas, Av. Washington Soares, 1321, Bloco S, Sala S-01, CEP 60811-905, Fortaleza, CE, Brazil Tel: +55 85 3477-3280

E-mail: geraldobezerrajr@yahoo.com.br

Received: 19 November 2019

Accepted: 21 January 2020

\section{Novel kidney injury biomarkers in tropical infections: a review of the literature}

\author{
Gdayllon Cavalcante Meneses ${ }^{1,2}$, Geraldo Bezerra da Silva Junior ${ }^{\circledR 3,4}$, Paulo \\ Pacelli Bezerra Filizola Tôrres ${ }^{4}$, Valeska Queiroz de Castro ${ }^{4}$, Renata Lima \\ Lopes $^{\circledR 3}$, Alice Maria Costa Martins ${ }^{2,4}$, Elizabeth De Francesco Daher $^{1}$
}

\section{ABSTRACT}

Tropical diseases are mainly found in the tropical regions of Asia, Africa and Latin America. They are a major Public Health problem in these regions, most of them are considered neglected diseases and remain as important contributors to the development of AKI (Acute Kidney Injury), which is associated with increased patients' morbidity and mortality. In most countries, kidney disease associated to tropical diseases is attended at health services with poor infrastructure and inadequate preventive measures. The long-term impacts of these infections on kidney tissue may be a main cause of future kidney disease in these patients. Therefore, the investigation of novel kidney injury biomarkers in these tropical diseases is of utmost importance to explain the mechanisms of kidney injury, to improve their diagnosis and prognosis, as well as the assessment to health systems by these patients. Since 2011, our group has been studying renal biomarkers in visceral and cutaneous leishmaniasis, schistosomiasis, leptospirosis and leprosy. This study has increased the knowledge on the pathophysiology of kidney disease in the presence of these infections and has contributed to the early diagnosis of kidney injury, pointing to glomerular, endothelial and inflammatory involvement as the main causes of the mechanisms leading to nephropathy and clinical complications. Future perspectives comprise establishing longterm cohort groups to assess the development of kidney disease and the patients' survival, as well as the use of new biomarkers such as urinary exosomes to detect risk groups and to understand the progression of kidney injuries.

KEYWORDS: Acute kidney injury. Biomarkers. Chronic kidney disease. Diagnosis. Hemodialysis. Neglected diseases. Neglected tropical diseases.

\section{INTRODUCTION}

Tropical infections are important causes of morbidity and mortality and a major public health problem, especially in tropical regions of Asia, Africa and Latin America. Kidneys may be injured on several occasions, complicating the course of many infectious and parasitic diseases ${ }^{1}$. Several types of renal abnormalities have been observed in patients with tropical diseases, including visceral leishmaniasis (kala-azar), dengue, leprosy, schistosomiasis, malaria and leptospirosis².

Although several types of nephropathies are detected in tropical diseases in different clinical contexts, the diagnosis of renal dysfunction is almost always late, being an important cause of medical complications. Moreover, the long-term impact of these infections on kidney tissues have never been investigated and may be a major cause of future kidney disease. 
Kidney injury mechanisms are not fully understood in many cases bringing major difficulties to specific therapeutic interventions. Worldwide, kidney injury identification is difficult, partly because of the low sensitivity of traditional diagnostic tests, such as serum creatinine measurement, being the condition often diagnosed only when the disease is fully established, with clear clinical signs and symptoms of renal dysfunction ${ }^{3}$.

Thus, it is of utmost importance to investigate new biomarkers that may be associated with the early identification of nephropathies observed in these infectious diseases. Many of these new renal biomarkers have been widely studied in the most common renal diseases but have been scarcely investigated in tropical diseases. Among them, the serum and urinary Neutrophil Gelatinase-Associated Lipocalin (NGAL), urinary Monocyte chemotactic peptide-1 (MCP-1), urinary Vascular Endothelial Growth Factor (VEGF) and serum Fibroblast Growth Factor-23 (FGF-23) are potential new renal biomarkers ${ }^{4-7}$. These renal biomarkers can provide important information regarding the location and chronicity of the kidney injury, and the early and specific identification of injury mechanism ${ }^{8}$.

Moreover, due to the particular characteristics of tropical diseases, other variables have become of great importance, such as inflammatory mediators and endothelial biomarkers, which are involved in several glomerulopathies. Proteinuria, for instance, may be the result of the loss of the glomerular endothelial glycocalyx layer, which is rich in negatively charged proteoglycans ${ }^{9}$. The release of syndecan-1 in plasma is a biomarker of endothelial glycocalyx injury that is present in these alterations ${ }^{10}$. Inflammatory mediators, such as interferon-gamma (IFN- $\gamma$ ), C-reactive protein (CRP), and interleukins 6 and 17 (IL-6; IL-17) are associated with renal events in infectious diseases such as visceral leishmaniasis, dengue hemorrhagic fever and leprosy ${ }^{11,12}$.

\section{METHODS}

This is a review of the literature on articles regarding kidney involvement in tropical diseases with focus on novel biomarkers of kidney injury, which are crucial for detecting this complication as early as possible. We have used the terms "acute kidney injury", "kidney diseases", "biomarkers", "neglected diseases" and the following infections: leishmaniasis, leprosy, schistosomiasis, leptospirosis and dengue. PubMed was the database we have used to perform the search, and the study comprised the period 2010-2019. We have also included the studies from our group to summarize the biomarkers we have investigated throughout the past years in the field of tropical infections.

\section{RESULTS}

\section{Tropical diseases and kidney complications}

Tropical infections continue to be an important cause of renal dysfunction, and some diseases show a significant frequency of acute kidney injury (AKI). It is likely that kidneys are particularly vulnerable to heat stress and to the re-emergence of water- and vector-borne infectious diseases. Examples include leptospirosis, leishmaniasis, leprosy, dengue, malaria and schistosomiasis. The contribution of AKI associated with infection in relation to other CKD factors has never been systematically evaluated. Research is needed to quantify the impact of infections on kidney health through prospective and cohort studies.

\section{Dengue}

Dengue is the most important mosquito-borne viral disease that affects humans in the tropical and subtropical regions worldwide. The infection can be asymptomatic or severe and fatal manifesting as dengue hemorrhagic fever (DHF), which is characterized by hemorrhagic events, thrombocytopenia and shock ${ }^{2}$.

During DHF, viral antigens have already been detected in several organs, including the kidneys ${ }^{12}$. Most studies of renal involvement during dengue infection have reported considerable mortality rates, especially in $\mathrm{DHF}^{13}$. Glomerular biopsies show abnormalities such as hypertrophy and hyperplasia of mesangial and endothelial cells in some glomerular capillary lumens and focal thickening of the glomerular basement membrane. In other cases, immune complex deposition in the glomerulus is a common histological finding ${ }^{14}$. Vascular alterations have also been observed and seem to be related to the imbalance of the host's immune response, as a consequence of the cytokines release profile and the type of cells present at the lesion $\operatorname{sites}^{15}$.

There are few studies on novel kidney injury biomarkers in dengue. Neutrophil gelatinase-associated lipocalin (NGAL) and resistin, a molecule associated to inflammation were significantly more elevated in patients with dengue, in comparison with healthy subjects ${ }^{16}$.

\section{Leishmaniasis}

Visceral leishmaniasis (kala-azar) is a chronic and lethal parasitic disease caused by intracellular parasites of the genus Leishmania. This is a zoonotic disease, typical of tropical areas, caused by Leishmania leishmania infantum chagasi, which is transmitted through a vector, an insect of the genus Lutzomyia ${ }^{17}$. 
Leishmania causes intense parasitism of the reticuloendothelial system and can be found in the liver, spleen, bone marrow, lymph nodes, lungs, kidneys and intestine. As a consequence of the parasitism, the patient has accentuated anemia, leukopenia, thrombocytopenia and increased plasma gamma globulin levels ${ }^{2}$.

Renal involvement in chronic visceral leishmaniasis (VL) is often associated with the progression of infection and increased mortality in these patients. The development of AKI hinders the clinical management of patients with VL and is associated to increased length of hospital stay, poor prognosis and mortality ${ }^{11,18}$.

In one of the first studies on VL nephropathy, the presence of proteinuria $<1 \mathrm{~g} / 24 \mathrm{~h}(57 \%)$, hematuria or leukocyturia $(51 \%)$ were reported in 50 patients $^{19}$. When performing the analysis of clinical findings due to renal dysfunction associated to VL in the literature, the following was observed: moderate proteinuria, hematuria, leukocyturia, microalbuminuria, hydroelectrolytic disorders such as hyponatremia, hypokalemia, hypochloremia, hypocalcemia, hypomagnesemia, increased excretion fraction of several electrolytes, and defects in urinary concentration and acidification $^{19-23}$. There is an induction of B-cell humoral immune activity, which has been associated with glomerular disease in kala-azar ${ }^{24}$. Consequently, antibodies produced in response to the infection may lead to immune complexes formation that deposit in the glomerulus and may induce a local inflammatory response, causing renal functional and structural abnormalities ${ }^{11}$.

Cutaneous leishmaniasis (CL) shows fewer renal alterations, as evidenced in the literature. The kidney injury mechanism that may occur also seems to be mediated by the deposition of immune complexes, formed after parasite destruction and formation of Donovan bodies. AKI occurs at a much lower frequency in CL when compared to $\mathrm{VL}$, and seems to be more associated to the leishmanicidal treatment ${ }^{25}$. An important study of our group in 37 patients with $\mathrm{CL}$ observed changes in the glomerular filtration rate and, especially, tubular defects, including defects in urinary concentration and acidification, as well as changes in the fraction of sodium, potassium, calcium and phosphorus excretions ${ }^{25}$.

\section{Leprosy}

Leprosy is another infectious disease with chronic evolution that has affected humanity for millennia, and to this day remains a major public health problem in many countries worldwide. The disease is caused by Mycobacterium leprae, an acid-fast bacillus, a mandatory intracellular microorganism that mainly affects the skin and peripheral nervous system, causing a wide variety of clinical and histopathological manifestations ${ }^{26}$. Depending on the degree and efficacy of cell-mediated immunity, patients may present with a single, well-delineated lesion (tuberculoid pole - paucibacillary) or, at the other end, with many and poorly delineated lesions of several types, such as papules, nodules, and macules (virchowian pole -multibacillary) ${ }^{27}$. The disease is currently divided into four clinical forms, according to the World Health Organization (WHO) criteria: undetermined, tuberculoid, dimorphic and Virchowian ${ }^{28}$.

Renal lesions in patients with leprosy were initially studied in autopsies of infected patients. The rate of renal alterations can be as high as $72 \%$ in these patients, especially in the Virchowian form, which is the most severe form of the disease ${ }^{29}$. Although clinical renal complications are uncommon and usually mild when present, they may be silent, as they have never been investigated, constituting long-term risk factors for the development of Chronic Kidney Disease in these patients ${ }^{30}$.

Only a few patients show a rapid decline in renal function or large proteinuria associated with edema. These uncommon cases were presented as case reports due to their rarity ${ }^{31}$. Glomerulonephritis seems to be the most common type of nephropathy in leprosy, accompanied by hematuria and increased proteinuria, especially in multibacillary forms $^{32,33}$. The exact mechanism leading to the development of glomerulopathy is not completely understood. M. leprae does not seem to be directly involved, although it has already been found in the glomeruli of some patients ${ }^{32}$. The most common glomerular histological change is mesangial proliferative glomerulonephritis, which is often associated to immune complex depositions ${ }^{34}$.

\section{Leptospirosis}

Leptospirosis is a disease caused by a microorganism of the genus Leptospira. In total, nine pathogenic species are known, including $L$. interrogans ${ }^{35}$. The early phase of leptospirosis manifestations lasts three to seven days and includes fever, headaches, myalgia (especially in calves), nausea, vomiting, malaise and conjunctival hyperemia. Only 10\% might progress to the second phase: Weil's syndrome, which lasts from four to 30 days, showing more severe symptoms, such as jaundice, meningitis, pulmonary hemorrhage and acute kidney injury ${ }^{36}$.

The kidney is one of the main targets of Leptospira, and kidney injury can occur in $20-85 \%$ of patients ${ }^{2}$. Clinical manifestations range from simple urinary sediment abnormalities to acute renal failure. Renal and glomerular tubular involvement may occur through several mechanisms, such as direct nephrotoxic action 
of Leptospira, hemodynamic alterations and decreased glomerular filtration rate and rhabdomyolysis ${ }^{35}$. Loss of urinary electrolytes may lead to hypomagnesemia and hypokalemia and tubular alterations usually precede the decrease in the GFR. AKI in leptospirosis is often nonoliguric and hypokalemic. The etiopathology of AKI is complex and multifactorial, including the direct effect of the bacterium on renal tissues, hypovolemia, hypotension, rhabdomyolysis, hyperbilirubinemia and endothelial glycocalyx damage ${ }^{1,2}$. Novel biomarkers in leptospirosis have been investigated, including neutrophil gelatinaseassociated lipocalin (NGAL), significantly associated to endothelial damage biomarkers (syndecan-1 and ICAM-1) ${ }^{9}$.

\section{Malaria}

Malaria is an important tropical disease, with great concern for Public Health, with most cases concentrated in Africa and in the Amazon forest region ${ }^{37-39}$. Malaria is associated to disease in glomeruli, tubules and in the interstitial region ${ }^{39}$. AKI in malaria is more frequent in infections caused by Plasmodium falciparum, and manifestations include oliguria, severe metabolic acidosis, hypercatabolic state and hydroelectrolytic disorders, such as hyponatremia and hyperkalemia ${ }^{39}$. The histopathological findings in malariaassociated AKI include acute tubular necrosis, interstitial nephritis, inflammatory interstitial infiltrate, edema and glomerulonephritis, and the pathogenesis is associated to blockade of renal microcirculation, hemodynamic factors and hypovolemia ${ }^{40-42}$.

Malaria was one of the first parasitic diseases described to be a directly involved with glomerulonephritis ${ }^{39}$, and proteinuria is a frequent finding among infected patients, varying from 20 to $50 \%$ of cases $^{43}$. Mesangial proliferation is the most frequent found pattern, with mild matrix expansion and deposits of eosinophilic material on the capillary walls in the mesangium and in Bowman's capsule. Immunofluorescence shows granular deposits of IgM and $\mathrm{C} 2$ in the capillaries and mesangium ${ }^{40,44}$. Collapsing focal and segmental glomerulosclerosis is a less frequent lesion observed in malaria, with a non-immune pattern ${ }^{45}$.

There are few studies investigating novel kidney injury biomarkers in malaria. Neutrophil gelatinase-associated lipocalin (NGAL) and kidney injury molecule-1 (KIM-1) have been investigated in P. falciparum infections ${ }^{46}$. Another study found increased KIM-1 and matrix metalloproteinase-3 (MMP-3) expression in tissues from autopsied patients with malaria-associated $\mathrm{AKI}^{47}$. Chitinase-3-like 1 (CHI3L1), a glycoprotein that has been recently proposed as a urinary biomarker for AKI, was also associated to AKI in children with severe malaria, and evidenced its association with mortality ${ }^{48}$. Approximately $31 \%$ of patients with malaria-associated AKI had normal levels of creatinine at presentation, illustrating the importance of new AKI biomarkers ${ }^{39}$.

\section{Schistosomiasis}

Schistosoma mansoni infection remains a major public health problem, affecting approximately 200 million people in more than 70 countries, mainly in Africa, Eastern Mediterranean and South America ${ }^{49}$.

Renal involvement in schistosomiasis is mainly described by a glomerular involvement. Schistosomal glomerulopathy is associated to the hepatosplenic form of the disease, but it has also been observed in the hepatic intestinal form ${ }^{50}$. The immunological nature of the glomerular involvement in schistosomiasis is well established. The most frequently reported histological types are chronic membranoproliferative glomerulonephritis, segmental and focal glomerulosclerosis, usually associated to nephrotic syndromes ${ }^{51}$. Besides the parasites antigens, there are other important factors that seem to contribute to the pathogenesis of glomerular diseases in schistosomiasis, such as the collateral circulation of the portal system due to the degree of hepatic involvement, the inefficiency of the hepatic macrophage system, the severity and duration of the infestation and genetic factors ${ }^{52}$. Monocyte Chemotactic Protein-1 (MCP-1) has been investigated in chronic schistosomiasis caused by S. mansoni, and there is evidence of association to subclinical kidney disease, with significant association to albuminuria ${ }^{53}$.

\section{The importance of early renal injury diagnosis}

Until recently, there were over thirty definitions of AKI in the literature, rendering comparisons of results among studies very difficult. The absence of a universally accepted definition resulted in a huge variation in the described incidence of AKI, rendering comparisons between different studies and populations difficult ${ }^{8}$. In 2004, the ADQI (Acute Dialysis Quality Initiative) group proposed a consensual definition for AKI: the RIFLE (Risk, Injury, Failure, Loss and End-stage Kidney Disease) classification. This is a classification system based on acute changes in serum creatinine measurements and/or variations in diuresis. It has three classes of severity (Risk, Injury and Failure) and two classes of evolution (loss and end-stage kidney disease $)^{54}$. In 2007, the Acute Kidney Injury Network (AKIN) classification was proposed, and revised this definition, suggesting minor changes based on the abrupt decrease in renal function (within $48 \mathrm{~h}$ ) and establishing a 
staging system in an attempt to define the degrees of renal dysfunction at the moment of diagnosis ${ }^{54,55}$.

More recently, the Kidney Disease Improving Global Outcomes (KDIGO) group has proposed a new definition including the increase in serum creatinine $(0.3 \mathrm{mg} / \mathrm{dL})$ during a 48-h period, similar to the definition proposed by the AKIN group. In addition, a 50\% increase in serum creatinine is considered within a seven days period, as suggested by the RIFLE criterion ${ }^{56}$.

However, the diagnosis of renal disease based on serum creatinine is still a late diagnosis, contributing to the high rates of $\mathrm{AKI}^{8}$. Clinical markers used to assess renal function, such as urinary volume and serum creatinine, are very limited due to extrarenal variables that interfere with their levels, and creatinine increases only occurs when half of the renal function is already impaired ${ }^{8,57}$.

Thus, the identification of kidney injury also becomes difficult due to the low sensitivity of diagnostic tests, being often diagnosed only when it is fully established, with evident clinical signs and symptoms. Early detection of patients at increased risk for acute renal dysfunction may be decisive for changing the clinical management and increasing patients' survival, thus reducing the incidence of unfavorable outcomes ${ }^{58}$. As a result, there has been an exponential increase in studies with new AKI biomarkers that could be earlier and more specific markers of kidney injury ${ }^{59}$.

\section{Novel kidney injury biomarkers}

Studies on new kidney injury biomarkers aimed to obtain important information regarding the location of the kidney injury, assessing the injury intensity, the differential diagnosis of the injury, its predictive capacity of AKI in new or hospitalized patients and the impacts of therapeutic interventions. Several new biomarkers candidates are being studied in different clinical contexts, showing greater specificity and sensitivity in relation to classic clinical renal markers ${ }^{60}$. They can be quantified in serum and urine samples, showing relevant results in both cases. Urine is ideal for these diagnostic and prognostic studies, as it is a noninvasive and easily collected biological specimen whereas serum is also an important specimen, as its systemic biomarkers can influence urinary levels or even be associated with kidney disease ${ }^{61,62}$.

Each new biomarker has advantages and disadvantages, but they are usually more specific to a specific part of the nephron, helping to detect the site of kidney injury and elucidate the nephrotoxic mechanisms. The combined evaluation of several biomarkers in the same clinical context can complement the pathophysiological information of each one of the parameters and improve not only the understanding of the nephropathy but also its clinical diagnosis ${ }^{8,58,63}$.

For AKI, the most often studied biomarkers are Neutrophil Gelatinase-Associated Lipocalin (NGAL), Kidney Injury Molecule-1 (KIM-1), FABP1 (Fatty AcidBinding Protein 1) and FGF-23 (fibroblast growth factor 23) (LEAF 2016). Other biomarkers are more specific for glomerulopathies ${ }^{8,63-66}$.

\section{Use of new biomarkers in tropical diseases}

Despite the increased risk of kidney disease and the infectious characteristic of tropical diseases, the use of new biomarkers for the detection and evaluation of prognosis in these patients has been scarce and has not followed the same pace as in other clinical contexts. In fact, this also characterizes these tropical diseases as neglected diseases for health services. Our group has been studying renal pathophysiology in these diseases and has evaluated different types of biomarkers over the past eight years, which could broaden the knowledge on the type of kidney injury, its early detection, risk groups for kidney disease and the mechanisms of kidney injury. Patients with cutaneous and visceral leishmaniasis, leptospirosis, schistosomiasis, and leprosy have already been studied.

In 2011, renal tubular dysfunction was shown for the first time in patients with Cutaneous Leishmaniasis (CL), as well as the association with the altered expression of renal tubular transporters and compensatory mechanisms of these dysfunctions ${ }^{67}$. In this study, urinary exosomes were evaluated to elucidate the etiology of urinary concentration and acidification failure found in apparently asymptomatic patients ${ }^{67}$. It was observed that defects in urinary concentration were caused by a decrease in the expression of aquaporins (AQP2), accompanied by a compensatory increase of the NKCC 2 transporter, responsible for sodium, potassium and chloride absorption into the interstitium, indicating problems of the AQP2 production in the collecting duct (Figure 1). On the other hand, acidification defects were evidenced by the increase in the apical exchanger pendrin of $\beta$ - intercalated cells in the cortical collecting duct. The pendrin secretes bicarbonate in the lumen and increases the urinary $\mathrm{pH}$. Moreover, compensatory mechanisms have also been demonstrated due to the increase in the NHE3 exchanger, which secretes $\mathrm{H}^{+}$ions in the lumen (Figure 1). However, the stratification of patients with these alterations and their long-term impacts on renal function has not yet been studied.

Glomerular involvement is very present in infectious diseases such as VL, and can be decisive for the development 
(a)

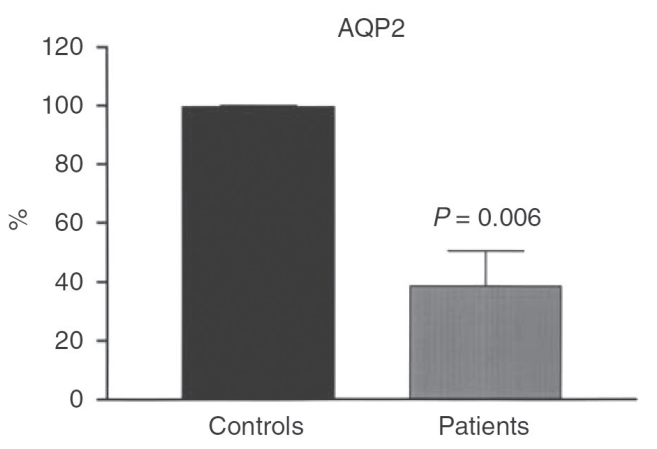

(c)

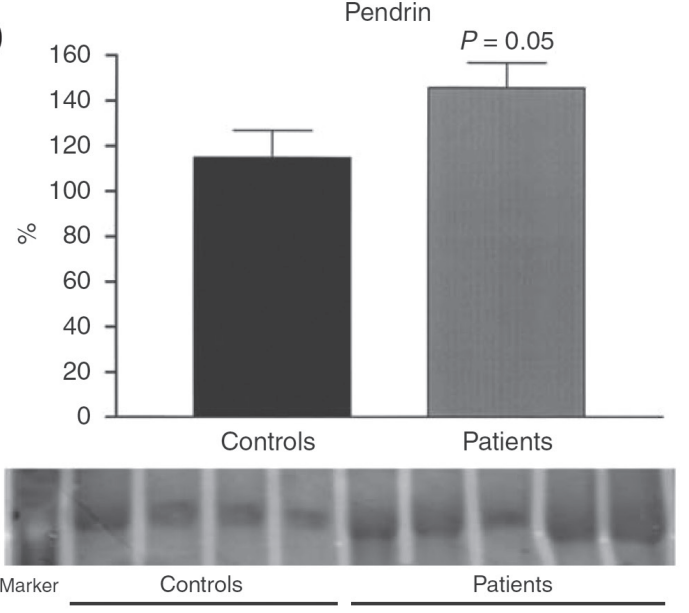

(b)
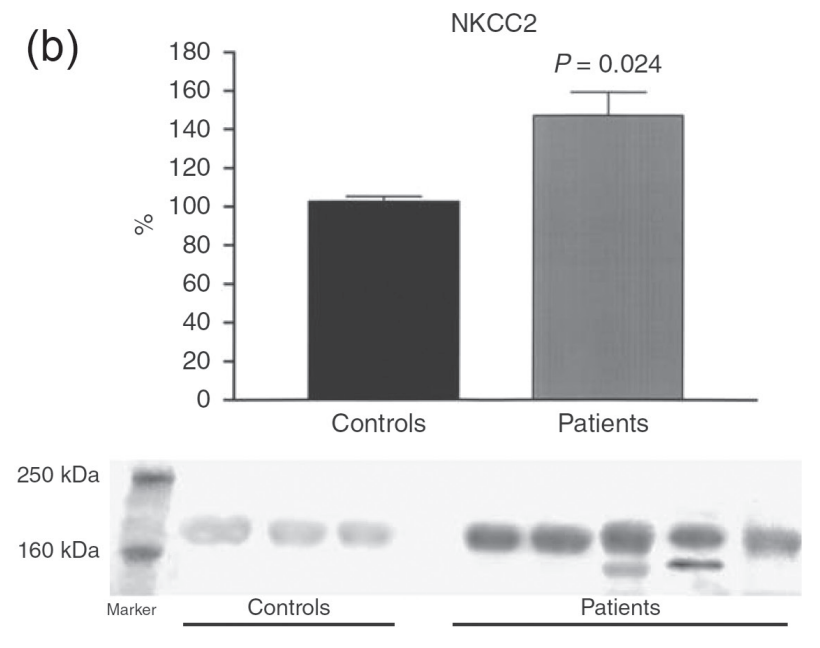

(d)
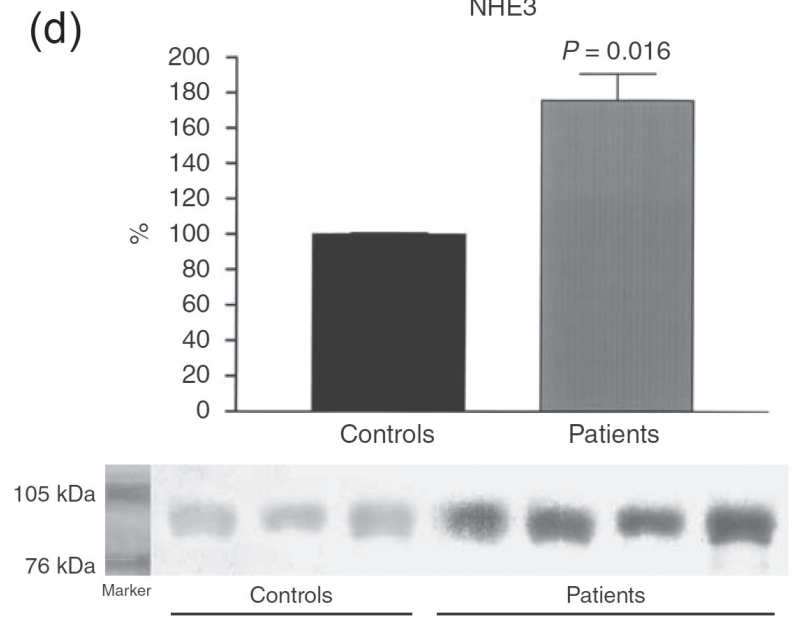

Figure 1 - At the top: Plenty of (a) aquaporin (AQP2); (b) Na-K-2Cl cotransporter (NKCC2); (c) pendrin; (d) Na / H exchanger (NHE3). Adapted from Oliveira et al. ${ }^{67}$, with permission, ${ }^{\odot 2011}$ International Society of Nephrology / Elsevier. At the bottom of (b),(c) and (d): Western blotting analysis of the urinary exosome fraction, normalized according to the urinary creatinine, in controls and in patients with American cutaneous leishmaniasis.

of AKI, contributing to the poor patient's prognosis. The investigation and elucidation of the mechanisms involved in glomerular structural and functional alterations may also help in the discovery of new kidney injury biomarkers and new therapeutic targets for these glomerulopathies.

In 2014, in a prospective study, we showed high levels of urinary MCP-1 and urinary oxidative stress in patients with visceral leishmaniasis who had normal serum creatinine, suggesting the presence of glomerular inflammation and incipient renal damage ${ }^{22}$. Another biomarker that seems to be reliable for the early detection of subclinical kidney injury in tropical diseases is NGAL, which had a good accuracy in a recent study from our group ${ }^{68}$.

Another study from our group showed early glomerular inflammation associated to increased proteinuria, albuminuria and renal oxidative stress in patients with leprosy, especially those with the virchowian form, suggesting that these patients had an increased risk of developing clinical kidney disease $\mathrm{e}^{30}$.

A summary of the main tropical infections, the novel biomarkers that have been already investigated and their implications in clinical practice is shown in Table 1.

\section{CONCLUSION}

Tropical infections are currently one of the most worrying problems in Public Health, greatly impacting on the development of kidney diseases and their complications. Biomarkers aiming to the early detection of kidney injury are crucial to help decreasing the burden of kidney diseases, especially in the developing world, where tropical diseases are most common and access to healthcare is often difficult, including access to kidney diseases treatment. Hence, early detection of kidney 
Table 1 - Tropical infections and novel biomarkers of acute kidney injury.

\begin{tabular}{|c|c|c|c|}
\hline Infection & Kidney involvement & $\begin{array}{l}\text { Novel biomarkers } \\
\text { already investigated }\end{array}$ & $\begin{array}{l}\text { Usefulness of the novel } \\
\text { biomarkers }\end{array}$ \\
\hline Dengue & AKI & NGAL, resistin & $\begin{array}{c}\text { Higher among patients } \\
\text { with dengue, evidence of } \\
\text { inflammation. }\end{array}$ \\
\hline Leishmaniasis & $\begin{array}{l}\text { AKI, proteinuria, hematuria, } \\
\text { leukocyturia, hydroelectrolytic } \\
\text { disorders, defects in urinary } \\
\text { concentration and acidification. }\end{array}$ & AQP2, NKCC2, NHE3 & $\begin{array}{l}\text { Detection of defects in tubular } \\
\text { transport. }\end{array}$ \\
\hline Leprosy & $\begin{array}{l}\text { Proteinuria, Glomerulonephritis, } \\
\text { AKI/CKD. }\end{array}$ & MCP-1 & $\begin{array}{c}\text { Association to AKI, } \\
\text { multibacillary forms and } \\
\text { oxidative stress. }\end{array}$ \\
\hline Leptospirosis & AKI & NGAL, Syndecan-1, ICAM-1 & AKI, Endothelial damage. \\
\hline Malaria & $\begin{array}{l}\text { AKI, Glomerulonephritis } \\
\text { (mesangial proliferation, } \\
\text { segmental and focal } \\
\text { glomerulosclerosis) }\end{array}$ & NGAL, KIM-1, MMP-3, CHI3L1 & $\begin{array}{c}\text { Early detection of malaria- } \\
\text { associated AKI; Association to } \\
\text { mortality. }\end{array}$ \\
\hline Schistosomiasis & $\begin{array}{c}\text { Glomerulonephritis } \\
\text { (membranoproliferative } \\
\text { glomerulonephritis, segmental } \\
\text { and focal glomerulosclerosis) }\end{array}$ & MCP-1 & $\begin{array}{c}\text { Association to subclinical } \\
\text { kidney disease, inflammation } \\
\text { and albuminuria. }\end{array}$ \\
\hline
\end{tabular}

AQP2 = aquaporin 2; CHI3L1 = matrix metalloproteinase-3; NGAL = Neutrophil gelatinase-associated lipocalin; NKCC2 = Na-K-Cl co-transporter; KIM-1 = kidney injury molecule-1; MCP-1 = monocyte chemotactic protein-1; NHE3 = Na/H co-transporter.

injury can prevent kidney disease progression, avoiding the need of expensive treatments such as dialysis and transplantation. It is possible that in the future, a "panel" of kidney injury biomarkers will be used in clinical practice, enabling the detection of any subclinical injury, from the glomeruli to any portion of the renal tubules.

\section{REFERENCES}

1. Burdmann EA, Jha V. Acute kidney injury due to tropical infectious diseases and animal venoms: a tale of 2 continents. Kidney Int. 2017;91:1033-46.

2. Daher EF, Barros E, Silva Junior GB. Nefrologia tropical. São Paulo: Balieiro; 2019.

3. Eaton DC, Pooler JP. Fisiologia renal de Vander. $8^{\mathrm{a}}$ ed. Porto Alegre: Artmed; 2016.

4. Leaf DE, Jacob KA, Srivastava A, Chen ME, Christiv M, Jüppner $\mathrm{H}$, et al. Fibroblast growth factor 23 levels associate with AKI and death in critical illness. J Am Soc Nephrol. 2016;28:187785.

5. Tufro A, Veron D. VEGF and podocytes in diabetic nephropathy. Semin Nephrol. 2012;32:385-93.

6. Kim MJ, Tam FW. Urinary monocyte chemoattractant protein-1 in renal disease. Clin Chim Acta. 2011;412:2022-30.

7. de Geus HR, Ronco C, Haase M, Jacob L, Lewington A, Vincent JL. The cardiac surgery-associated neutrophil gelatinaseassociated lipocalin (CSA-NGAL) score: a potential tool to monitor acute tubular damage. J Thorac Cardiovasc Surg. 2016;151:1476-81.

8. Parikh CR, Mansour SG. Perspective on clinical application of biomarkers in AKI. J Am Soc Nephrol. 2017;28:1677-85.

9. Libório AB, Braz MB, Seguro AC, Meneses GC, Neves FM, Pedrosa DC, et al. Endothelial glycocalyx damage is associated with leptospirosis acute kidney injury. Am J Trop Med Hyg. 2015;92:611-6.

10. Larsen AM, Leinøe EB, Johansson PI, Birgens H, Ostrowski SR. High syndecan-1 levels in acute myeloid leukemia are associated with bleeding, thrombocytopathy, endothelial cell damage, and leukocytosis. Leuk Res. 2013;37:777-83.

11. Silva Junior GB, Barros EJ, Daher EF. Kidney involvement in leishmaniasis: a review. Braz J Infect Dis. 2014;18:434-40.

12. Pagliari C, Simões Quaresma JA, Kanashiro-Galo L, Carvalho LV, Vitoria WO, Silva WL, et al. Human kidney damage in fatal dengue hemorrhagic fever results of glomeruli injury mainly induced by IL17. J Clin Virol. 2016;75:16-20.

13. Lee IK, Liu JW, Yang KD. Clinical characteristics, risk factors, and outcomes in adults experiencing dengue hemorrhagic fever complicated with acute renal failure. Am J Trop Med Hyg. 2009;80:651-5.

14. Futrakul P, Poshyachinda V, Mitrakul C, Kun-Anake C, Boonpucknavig V, Boompucknavig S, et al. Renal involvement and reticulo-endothelial-system clearance in dengue hemorrhagic fever. J Med Assoc Thai. 1973;56:33-9.

15. Costa VV, Fagundes CT, Souza DG, Teixeira MM. Inflammatory 
and innate immune responses in dengue infection: protection versus disease induction. Am J Pathol. 2013;182:1950-61.

16. Liu KT, Liu YH, Lin CY, Tsai MJ, Hsu YL, Yen MC, et al. Serum neutrophil gelatinase-associated lipocalin and resistin are associated with dengue infection in adults. BMC Infect Dis. 2016;16:441.

17. van Griensven J, Diro E. Visceral leishmaniasis. Infect Dis Clin North Am. 2012;26:309-22.

18. Clementi A, Battaglia G, Floris M, Castellino P, Ronco C, Cruz DN. Renal involvement in leishmaniasis: a review of the literature. NDT Plus. 2011;4:147-52.

19. Daher EF, Evangelista LF, Silva Júnior GB, Lima RS, Aragão EB, Arruda GA, et al. Clinical presentation and renal evaluation of human visceral leishmaniasis (Kala-azar): a retrospective study of 57 patients in Brazil. Braz J Infect Dis. 2008;12:329-32.

20. Daher EF, Rocha NA, Oliveira MJ, Franco LF, Oliveira JL, Silva Junior GB, et al. Renal function improvement with pentavalent antimonial agents in patients with visceral leishmaniasis. Am J Nephrol. 2011;33:332-6.

21. Oliveira MJ, Silva Júnior GB, Abreu KL, Rocha NA, Garcia AV, Franco LF, et al. Risk factors for acute kidney injury in visceral leishmaniasis (Kala-Azar). Am JTrop Med Hyg. 2010;82:449-53.

22. Oliveira MJ, Silva Junior GB, Sampaio AM, Montenegro BL, Alves MP, Henn GA, et al. Preliminary study on tubuloglomerular dysfunction and evidence of renal inflammation in patients with visceral leishmaniasis. Am J Trop Med Hyg. 2014;91:908-11.

23. Elnojomi NA, Musa AM, Younis BM, Elfaki ME, El-Hassan AM, Khalil EA. Surrogate markers of subtle renal injury in patients with visceral leishmaniasis. Saudi J Kidney Dis Transpl. 2010;21:872-5.

24. Costa FA, Prianti MG, Silva TC, Silva SM, Guerra JL, Goto H. $\mathrm{T}$ cells, adhesion molecules and modulation of apoptosis in visceral leishmaniasis glomerulonephritis. BMC Infect Dis. 2010;10:112.

25. Oliveira RA, Lima CG, Mota RM, Martins AM, Sanches TR, Seguro AC, et al. Renal function evaluation in patients with American cutaneous leishmaniasis after specific treatment with pentavalent antimonial. BMC Nephrol. 2012;13:44.

26. Suzuki K, Akama T, Kawashima A, Yoshihara A, Yotsu RR, Ishii N. Current status of leprosy: epidemiology, basic science and clinical perspectives. J Dermatol. 2012;39:121-9.

27. Britton WJ, Lockwood DN. Leprosy. Lancet. 2004;363:1209-19.

28. World Health Organization. WHO expert committee on leprosy: eighth report. Geneva: WHO; 2012.

29. Nakayama EE, Ura S, Negrão RN, Soares V. Renal lesions in leprosy: a retrospective study of 199 autopsies. Am J Kidney Dis. 2001;38:26-30.

30. Meneses GC, Libório AB, Daher EF, Silva Junior GB, Costa MF, Pontes MA, et al. Urinary monocyte chemotactic protein-1 (MCP-1) in leprosy patients : increased risk for kidney damage. BMC Infect Dis. 2014;14:451.
31. Silva Junior GB, Barbosa AO, Barros RM, Carvalho PR, Mendoza TR, Barreto DM, et al. Amiloidose e insuficiência renal crônica terminal associada à hanseníase. Rev Soc Bras Med Trop. 2010;43:474-6.

32. Ahsan N, Wheeler DE, Palmer BF. Leprosy-associated renal disease: case report and review of the literature. J Am Soc Nephrol. 1995;5:1546-52.

33. Chugh KS, Damle PB, Kaur S, Shama BK, Kumar B, Sakhuja V, et al. Renal lesions in leprosy amongst north Indian patients. Postgrad Med J. 1983;59:707-11.

34. Silva Junior GB, Daher EF. Renal involvement in leprosy: retrospective analysis of 461 cases in Brazil. Braz J Infect Dis. 2006;10:107-12.

35. Daher EF, Soares DS, Fernandes AT, Girão MM, Sidrim $\mathrm{PR}$, Pereira ED, et al. Risk factors for intensive care unit admission in patients with severe leptospirosis: a comparative study according to patients' severity. BMC Infect Dis. 2016;16:40.

36. Srisawat N, Praditpornsilpa K, Patarakul K, Techapornrung M, Daraswang T, Sukmark T, et al. Neutrophil Gelatinase Associated Lipocalin (NGAL) in leptospirosis acute kidney injury: a multicenter study in Thailand. PLoS One. 2015;10:e143367.

37. World Health Organization. World malaria report 2017. Geneva: WHO; 2017.

38. World Health Organization. Severe malaria. Trop Med Int Health. 2014;19 Suppl 1:7-131.

39. Silva Junior GB, Pinto JR, Barros EJ, Farias GM, Daher EF. Kidney involvement in malaria: an update. Rev Inst Med Trop Sao Paulo. 2017;59:e53.

40. Elsheikha HM, Sheashaa HA. Epidemiology, pathophysiology, management and outcome of renal dysfunction associated with plasmodia infection. Parasitol Res. 2007;101:1183-90.

41. Nguansangiam S, Day NP, Hien TT, Mai NT, Chaisri U, Riganti $\mathrm{M}$, et al. A quantitative ultrastructural study of renal pathology in fatal Plasmodium falciparum malaria. Trop Med Int Health. 2007;12:1037-50.

42. Koopmans LC, van Wolfswinkel ME, Hesselink DA, Hoorn EJ, Koelewijn R, van Hellemond JJ, et al. Acute kidney injury in imported Plasmodium falciparum malaria. Malar J. 2015; 14:523.

43. Olowu WA, Ademola A, Ajite AB, Saad YM. Childhood nephrotic syndrome in tropical Africa: then and now. Paediatr Int Child Health. 2017;37:259-68.

44. Barsoum R, Fayad T, Praditpornsilpa K, Sitprija V. Tropical nephrology. In: Coffman T, Falk R, Molitoris B, Neilson E, Schrier R, editors. Schrier's diseases of the kidney. $9^{\text {th }}$ ed. Philadelphia: Lippincott Williams \& Wilkins; 2013. p.1800-44.

45. Sehar N, Gobran E, Elsayegh S. Collapsing focal segmental glomerulosclerosis in a patient with acute malaria. Case Rep Med. 2015;2015:420459. 
46. van Wolfswinkel ME, Koopmans LC, Hesselink DA, Hoorn EJ, Koelewijn R, van Hellemond JJ, et al. Neutrofil gelatinaseassociated lipocalin (NGAL) predicts the occurrence of malaria-induced acute kidney injury. Malar J. 2016;15:464.

47. Punsawad C, Viriyavejakul P. Increased expression of kidney injury molecule- 1 and matrix metalloproteinase- 3 in severe Plasmodium falciparum malaria with acute kidney injury. Int J Clin Exp Pathol. 2017;10:7856-64.

48. Conroy AL, Hawkes MT, Elphinstone R, Opoka RO, Namasopo $\mathrm{S}$, Miller C, et al. Chitinase-3-like 1 is a biomarker of acute kidney injury and mortality in paediatric severe malaria. Malar J. 2018;17:82.

49. Chitsulo L, Loverde P, Engels D. Schistosomiasis. Nat Rev Microbiol. 2004;2:12-3.

50. Silva Junior GB, Duarte DB, Barros EJ, Daher EF. Schistosomiasisassociated kidney disease: a review. Asian Pac J Trop Dis. 2013;3:79-84.

51. Barsoum RS. Schistosomal glomerulopathies. Kidney Int. 1993;44:1-12.

52. Duarte DB, Vanderlei LA, Bispo RK, Pinheiro ME, Silva Junior GB, Martins AM, et al. Renal function in hepatosplenic schistosomiasis: an assessment of renal tubular disorders. PLoS One. 2014;9:e115197.

53. Hanemann AL, Libório AB, Daher EF, Martins AM, Pinheiro MC, Sousa MS, et al. Monocyte chemotactic protein-1 (MCP-1) in patients with chronic schistosomiasis mansoni: evidences of subclinical renal inflammation. PLoS One 2013;8:e80421.

54. Bellomo R, Ronco C, Kellum JA, Mehta RL, Palevsky P. Acute renal failure - definition, outcome measures, animal models, fluid therapy and information technology needs: the Second International Consensus Conference of the Acute Dialysis Quality Initiative (ADQI) Group. Crit Care. 2004;8:R204-12.

55. Mehta RL, Kellum JA, Shah SV, Molitoris BA, Ronco C, Warnock DG, et al. Acute Kidney Injury Network: report of an initiative to improve outcomes in acute kidney injury. Crit Care. 2007;11:R31.

56. Khwaja A. KDIGO Clinical Practice Guidelines for Acute Kidney Injury. Nephron Clin Pract. 2012;120:c179-84.

57. Vaidya VS, Ferguson MA, Bonventre JV. Biomarkers of acute kidney injury. Annu Rev Pharmacol Toxicol. 2008;48:463-93.
58. Ronco C, Rizo-Topete L, Serrano-Soto M, Kashani K. Pro: prevention of acute kidney injury: time for teamwork and new biomarkers. Nephrol Dial Transplant. 2017;32:408-13.

59. McCullough PA, Bouchard J, Waikar SS, Siew ED, Endre ZH, Goldstein SL, et al. Implementation of novel biomarkers in the diagnosis, prognosis, and management of acute kidney injury: executive summary from the tenth consensus conference of the Acute Dialysis Quality Initiative (ADQI). Contrib Nephrol. 2013;182:5-12.

60. Kashani K, Cheungpasitporn W, Ronco C. Biomarkers of acute kidney injury: the pathway from discovery to clinical adoption. Clin Chem Lab Med. 2017;55:1074-89.

61. Gonzales P, Pisitkun T, Knepper MA. Urinary exosomes: is there a future? Nephrol Dial Transplant. 2008; 23:1799-801.

62. Mårtensson J, Martling CR, Bell M. Novel biomarkers of acute kidney injury and failure: clinical applicability. Br J Anaesth. 2012;109:843-50.

63. Urbschat A, Obermüller N, Haferkamp A. Biomarkers of kidney injury. Biomarkers. 2011;16 Suppl 1:S22-30.

64. Ichimura T, Bonventre JV, Bailly V, Wei H, Hession CA, Cate RL, et al. Kidney injury molecule-1 (KIM-1), a putative epithelial cell adhesion molecule containing a novel immunoglobulin domain, is up-regulated in renal cells after injury. J Biol Chem. 1998;273:4135-42.

65. Mishra J, Dent C, Tarabishi R, Mitsnefes MM, Ma Q, Kelly C, et al. Neutrophil gelatinase-associated lipocalin ( NGAL ) as a biomarker for acute renal injury after cardiac surgery. Lancet. 2005;365:1231-8.

66. Haase M, Haase-Fielitz A. NGAL: from discovery to a new era of "acute renal disease" diagnosis? Clin Biochem. 2011;44:499500 .

67. Oliveira RA, Diniz LF, Teotônio LO, Lima CG, Mota RM, Martins A, et al. Renal tubular dysfunction in patients with American cutaneous leishmaniasis. Kidney Int. 2011;80:1099-106.

68. Meneses GC, Daher EF, Silva Junior GB, Bezerra GF, Rocha TP, Azevedo IE, et al. Visceral leishmaniasis-associated nephropathy in hospitalised Brazilian patients: new insights based on kidney injury biomarkers. Trop Med Int Health. 2018;23:1046-57. 